\title{
Bite Registration Accuracies with Intraoral Scanning
}

\author{
Pravinkumar G Patil \\ International Journal of Prosthodontics and Restorative Dentistry (2020): 10.5005/jp-journals-10019-1284
}

Digital impressions by intraoral scanning (IOS) have become an increasingly popular alternative to conventional or analog impressions. The collective evidence from a total of 132 studies (20 reviews, 78 clinical, and 34 in vitro) suggested that the current IOS is sufficiently accurate for fabricating a whole series of (a tooth or implant-supported) prosthetic restorations except the long-span restorations. ${ }^{1}$ However, there is still a huge lacuna in the literature related to the clinical evidence on accuracies of bite registration with the IOS. Porter et al. ${ }^{2}$ evaluated the accuracy of model articulation generated by one extraoral scanner with wax or vinyl polysiloxane bite registration, and three intraoral digital scanners utilizing confocal static, confocal continuous, and blue LED light technologies. They concluded that confocal imaging technology scanners produced accurately articulated models. Yee et al. ${ }^{3}$ evaluated the 3D static articulation accuracy of three model scanner-CAD systems using a coordinate measuring machine and concluded that the overall interarch global distortion did not exceed $0.6 \%$. Edher et al. ${ }^{4}$ evaluated the accuracy of virtual interocclusal registration records made at different locations around the arch and found out that occlusal contacts obtained from interocclusal registration scans for quadrant scans had a higher sensitivity than did those for complete-arch scans. Wong et al. ${ }^{5}$ compared the three-dimensional accuracy of the digital static interocclusal registration of three IOS systems using the buccal bite scan function. They observed both interarch and interocclusal distortions that could affect the magnitude of occlusal contacts of restorations clinically and suggested the need for compensations during the CAD design stage or at restoration issue appointment. Gintaute et al. ${ }^{6}$ carried out in vitro study to evaluate the accuracy of bite registration produced by three intraoral scanners (CEREC, TRIOS, and PLANMECA) with six dental models scanned five times. They observed that the bite registrations from all three intraoral scanners created significantly different surface areas of full arch occlusal contacts. Posterior occlusions revealed lower precision for all scanners than anterior. Not many clinical studies have been carried out to evaluate the accuracies of virtual bite registration. Abdulateef et al. ${ }^{7}$ compared the accuracy and reproducibility of the virtual interocclusal records of the IOS with conventional polyvinyl siloxane (PVS) interocclusal records. They concluded that although the IOS records are clinically acceptable, this method tends to introduce false contacts resulting in perforations between the opposing virtual casts. Repeated buccal occlusal scans showed fair reproducibility.
Department of Prosthodontics, Division of Clinical Dentistry, School of Dentistry, International Medical University, Kuala Lumpur, Malaysia Corresponding Author: Pravinkumar G Patil, Department of Prosthodontics, Division of Clinical Dentistry, School of Dentistry, International Medical University, Kuala Lumpur, Malaysia, Phone: +60 1135022042, e-mail: pravinandsmita@yahoo.co.in

How to cite this article: Patil PG. Bite Registration Accuracies with Intraoral Scanning. Int J Prosthodont Restor Dent 2020;10(3):94.

Source of support: Nil

Conflict of interest: None

Looking at the current literature, the pieces of evidence are being built around the products and technologies to meet the need of specific restoration types. The measurement errors are inherent to the technologies employed and the software systems used to process the images. ${ }^{2}$ Variations in virtual articulation algorithm and scanner technology may contribute to the possible distortions in digital interocclusal records. ${ }^{3}$ Dental practitioner must be mindful in integrating specific IOS system in practice by studying scientific evidence in relation to specific prosthetic type and span to make clinically acceptable restorations.

\section{References}

1. Mangano F, Gandolfi A, Luongo G, et al. Intraoral scanners in dentistry: a review of the current literature. BMC Oral Health 2017;17(1):149. DOI: 10.1186/s12903-017-0442-x.

2. Porter JL, Carrico CK, Lindauer SJ, et al. Comparison of intraoral and extraoral scanners on the accuracy of digital model articulation. J Orthod 2018;45(4):275-282. DOI: 10.1080/14653125.2018.1500773.

3. Yee SHX, Esguerra RJ, Chew AAQ, et al. Three-dimensional static articulation accuracy of virtual models - part I: system trueness and precision. J Prosthodont 2018;27(2):129-136. DOI: 10.1111/jopr.12723.

4. Edher F, Hannam AG, Tobias DL, et al. The accuracy of virtual interocclusal registration during intraoral scanning. J Prosthet Dent 2018;120(6):904-912. DOI: 10.1016/j.prosdent.2018.01.024.

5. Wong KY, Esguerra RJ, Chia VAP, et al. Three-dimensional accuracy of digital static interocclusal registration by three intraoral scanner systems. J Prosthodont 2018;27(2):120-128. DOI: 10.1111/jopr.12714.

6. Gintaute A, Keeling AJ, Osnes CA, et al. Precision of maxillomandibular registration with intraoral scanners in vitro. J Prosthodont Res 2020;64(2):114-119. DOI: 10.1016/j.jpor.2019.05.006.

7. Abdulateef S, Edher F, Hannam AG, et al. Clinical accuracy and reproducibility of virtual interocclusal records. J Prosthet Dent 2020;124(6):667-673. DOI: 10.1016/j.prosdent.2019.11.014. 